\title{
Does household food insecurity influence nutritional practice of children age 6 to 23 months in Bangladesh?
}

\author{
Mohammad Rocky Khan Chowdhury ${ }^{1}$, Russell Kabir ${ }^{2}$, Konstantinos Papadopoulos ${ }^{3}$, S. M. Yasir \\ Arafat ${ }^{4}$, Manzur Kader ${ }^{5}$, Mohbub Alam ${ }^{6}$, Md. Nazrul Islam Mondal
}

\begin{abstract}
${ }^{1,6}$ Lecturer, Department of Public Health, First Capital University of Bangladesh, Chuadanga, Bangladesh. ${ }^{2}$ Senior Lecturer; ${ }^{3}$ Lecturer; Department for Allied and Public Health, Anglia Ruskin University, Chelmsford, Essex, UK. ${ }^{4}$ Resident, Department of Psychiatry, Bangabandhu Sheikh Mujib Medical University, Dhaka, Bangladesh. ${ }^{5}$ Researcher, Department of Health Sciences, Faculty of Medicine, Lund University, Lund, Sweden. ${ }^{7}$ Department of Population Science and Human Resource Development, University of Rajshahi, Bangladesh.
\end{abstract}

\section{Abstract}

To examine the prevalence of household food insecurity (HHFI) among children aged between 6-23 months in Bangladesh. This paper also aims to identify the individual, household and community levels determinants of HHFI and the association between nutritional behavior and HHFI. Bangladesh Demographic Health Survey (BDHS), 2011 was used for this research. A total of 2,344 children were selected for analysis. Statistical analysis and tests were guided by the nature of the variables. Finally, logistic regression analysis was used to find out the association between independent variables and outcome. The overall prevalence of HHFI was 36.3\% (95\% CI: 33.6-39.0) among the participants (children). The prevalence of HHFI was significantly higher among children who did not receive nutritional items. In contrast, HHFI was more prevalent among children who were breastfed (37.0\%) as compared to non-breastfed. Binary logistic regression analysis showed that children of illiterate mothers (adjusted OR: 2.20, 95\% CI: 1.17-4.10), illiterate fathers (adjusted OR: 2.27, 95\% CI: 1.41-3.66) and socio-economically poor families (adjusted OR: 11.35, 95\% CI: 7.20-17.91) were more at risk of experiencing HHFI, whereas, rural children (adjusted OR: $0.72,95 \%$ CI: $0.57-0.93$ ) were more protective. In the adjusted logistic regression model, children who did not receive juice (adjusted OR: 1.54, 95\% CI: 1.09-2.16) had experienced HHFI. The prevalence of HHFI among children is still high in Bangladesh. Therefore, to achieve the Millennium Development Goals, the Government of Bangladesh should priorities HHFI as a major public health issue. Strong collaborations among various stakeholders are also crucial to improve the situation.

Keywords: Household food insecurity, Children, Nutrition, MDG, Bangladesh.

\section{Introduction}

Household food insecurity (HHFI) refers to the insufficient access of nutritionally safe and adequate foods to meet dietary needs and food preferences for an active and healthy life. ${ }^{1}$ Although Bangladesh is on its way of achieving the Millennium Development Goals (MDGs) (the substantial reduction of hunger, poverty and maternal and child mortality by the year 2015), improvements in the child nutritional status have been less impressive. ${ }^{2}$ The prevalence of under-five child malnutrition in Bangladesh is nearly $40 \%$, which is one of the world's highest and causes around $60 \%$ of under-five deaths. $^{3}$ Poor nutritional status of children is associated with a variety of factors, such as, household food unavailability, improper nutritional practice, unavailability of services and social issues. ${ }^{2,4}$ Nearly $30 \%$ of Bangladeshis have a lack of income and live below the poverty line. This results in them being vulnerable to household food insecurity (HHFI). ${ }^{5}$ In Bangladesh, over $60 \%$ of all pregnant and lactating women produce underweight children due to insufficient caloric intake ${ }^{6}$

About 6 to 23 months of age of child development is a 'critical window' for the transition of body and cognitive development ${ }^{7}$. At this stage, children should be fed small quantities of nutritional solid and semisolid foods in addition to breastfeeding. ${ }^{7}$ Proper and adequate feeding practices during infancy and early childhood are fundamental for the growth, development, and survival of

\section{Practice Points}

- Household food insecurity (HHFI) refers to the insufficient access of nutritionally safe and adequate foods to meet dietary needs and food preferences for an active and healthy life.

- Socioeconomically poor families were more at risk of experiencing household food insecurity.

- Food insecurity was more prevalent among children of illiterate parents and higher prevalence of breastfeed children were found to suffer food insecurity.

- Bangladeshi women in rural areas are responsible to ensure the food requirements of their dependents.

- Strong collaborations among various stakeholders are also crucial to improve the situation.

infants and children, particularly in developing countries. ${ }^{8,9}$ Evidence shows that HHFI is associated with a high prevalence of inadequate intake of key nutrients, resulting in a wide variety of adverse health and development outcomes in children. ${ }^{10,11}$ In Bangladesh, approximately $50 \%$ of all children aged 6 -24 months do not receive the minimum meal frequency (eating 3 meals a day or more). ${ }^{12}$ More than $60 \%$ of

Correspondence: Dr. Russell Kabir, Senior Lecturer in Research Methods, Department for Allied and Public Health, Anglia Ruskin University, Chelmsford, Essex, UK. Email: russell.kabir@,anglia.ac.uk. 
Bangladeshi children did not meet the minimum recommended dietary diversity per day (proportion of children who receive foods from World Health Organization (WHO) recommended four or more food groups). ${ }^{12}$

Over one billion people (which accounts for over $20 \%$ of global population), mainly in the developing world, are food insecure. Over 15 million people, mostly children, die from hunger, poverty and malnutrition every year. ${ }^{13}$ Children growing up in food insecure families are more susceptible to diseases that adversely affect a country's long term economic, social and political development. ${ }^{14,15}$ Household food security (HHFS) is affected by the various social determinants, such as, education, poverty, gender, age and disability, geographical location and cultural practices. ${ }^{6}$

The aim of this study was to identify the association between the nutritional practice of children 6-23 months of age and HHFI together with identifying the multilevel determinants of HHFI. Multiple studies already have highlighted the significance of the relationship between CFP and HHFI, for example, dos Santos \& Gigante $^{16}$ showed the relationship between food insecurity and the nutritional status of Brazilian children aged under-five years old. Lindsay et al. ${ }^{17}$ identified the association between HHFS and a mothers' child feeding behavior in a qualitative study. In Argentina, Osei et $a l{ }^{18}$ examined the relationship between HHFS and dietary diversity of children and Saha et al. ${ }^{19}$ showed the association between HHFS and change in CFP in different age groups in Bangladesh. To our knowledge, no previous studies in Bangladesh have focused substantially on the relationship between the nutritional behavior of children and HHFI using a nationally representative sample. Considering the limited number of studies and formulations of effective policy decision for the society, it is essential to establish a comprehensive relationship between nutritional practice among children and HHFI.

\section{Materials and methods}

\section{Sources of data}

The data used in this study was extracted from the Bangladesh Demographic Health Survey (BDHS) 2011, which was a nationally representative cross-sectional survey. The data was collected in five phases, starting on July 8 and ending on December 27, 2011. The BDHS 2011 was conducted by the National Institute of Population Research and Training (NIPORT) under the Ministry of Health and Family Welfare. It was implemented by a Bangladeshi research firm 'Mitra and Associates'. Technical support was provided by ICF International of Calverton, Maryland, USA and financial support was afforded by USAID. The BDHS was based on adult household data. The survey was undertaken in seven administrative regions (divisions): Barisal, Chittagong, Dhaka, Khulna, Rajshahi, Rangpur and Sylhet (covering both rural and urban areas). Enumeration areas from the most recent census were used as the Primary Sampling Units (PSUs) for the survey. Multistage stratified sampling technique was used. At the first stage of sampling, 600 PSUs were selected (393 rural PSUs and 207 urban PSUs). The resulting lists of households were used as the sampling frame for the selection of households in the second stage of sampling. The detail sampling design and other related issues of BDHS are described in another study. ${ }^{20}$

\section{Sample size selection}

A total of 8,761 children under 5 years of age were considered for anthropometric measurements, of which anthropometric and age data were complete for 7,647 children (around 88\%). From the total of 2,405 children aged 6-23 months in BDHS (2011), 61 children were excluded due to missing information e.g. children of mothers who responded "do not know" for nutritional practice. Therefore, the final sample for analysis was 2,344 .

\section{Outcomes}

We selected five household food security indicators using the Household Food Insecurity Access Scale (HFIAS) and included these in a questionnaire. This was then given to and answered by mothers of the children included in the BDHS-2011 survey. ${ }^{20}$ The technical working group of the BDHS-2011 (11) systematically reviewed and modified the indicators used in the HFIAS to ensure that the included indicators were relevant and specific to Bangladesh. Participants were asked five questions about their food intake in the last 12 months: 1) how often they had three square (full stomach) meals a day; 2) whether they skipped entire meals because there was not enough food; 3) whether they had smaller meals because there was insufficient food; 4) whether the mother or any other family members ate wheat or another grain in place of rice and 5 ) if they had asked relatives or neighbors for food to make a meal. Each indicator had four response options: never ( 0 times in the past 12 months), rarely (1-6 times in the past 12 months), sometimes (7-12 times in the past 12 months) and often (a few times each month). A household was classified as food insecure if the respondent answered sometimes, often, or never to question one and answered rarely, sometimes or often to questions two to five. A household that did not meet these conditions, and scored zero, was classified as food secure. Individual food frequency scores for all the five frequency responses were added together to provide a single food security score for each woman in the household who was married. To facilitate the analysis, a composite score ranging from a minimum of zero to a maximum of 15 was calculated and classified as a dichotomous score, with zero representing food secure and a score of more than zero representing food insecure.

\section{Covariates}

Three levels of characteristics, such as, individual, household, and community characteristics were included in this study. Individual level characteristics included the age of the child (6-11 months, 12-17 months, 18-23 months); sex of the child (male, female); mother's educational status (no education, primary, secondary, higher); father's educational status (no education, primary, secondary, higher). Household socio-economic status based on wealth index (poorest, poorer, middle, richer, and richest) was considered as the household-level characteristics. The wealth index was constructed using household asset data via principal components analysis. ${ }^{20}$ Community-level characteristics included place of residence (urban, or rural).

For nutritional indicators, the authors included 17 frequently asked questions (indicators) for mothers of households (Figure 1). Among them 16 food items were 
listed (excluding breastfeeding) which could have been received by the children within 24-hours prior to the interview. For each question, responses were coded binary as $1=$ given/yes and $0=$ not given/no.

\section{Statistical analysis}

Descriptive statistics were presented as percentages for HHFI, multilevel characteristics and nutritional behavior. Chi-square test and binary logistic regression were used to evaluate the association between outcome and independent variables (covariates). Stata version 11.2/SE (Stata Corp, College Station, Texas, USA) was used for all statistical analysis. All analyses were statistically significant at 5\% level.

\section{Results}

The summary of the study findings are presented in Table 1. It is found that among the children, $50.55 \%$ were male, $21.07 \%$ were from socio-economically poor families and $69.28 \%$ were living in rural areas.

Nutritional practice of children

Figure 1 showed that around $94.8 \%$ children were breastfed. A higher percentage was recorded for micronutrients/foods like bread, noodles or others made from grains $(75.9 \%)$; vitamins. On the contrary, a lower percentage was observed for foods, such as, cheese, yogurt, and/or other milk products $(1.5 \%)$.

Prevalence of HHFI (bivariate analysis based on Chisquare test)

An estimated of $36.3 \%$ children aged 6-23 months were food insecure (Table 2). The prevalence of HHFI was found to be significantly higher among children of illiterate mothers $(58.5 \%)$, illiterate father $(52.7 \%)$, socio-economically poor families $(63.0 \%)$ and rural settlement (39.6\%).

In Table 3, the prevalence of HHFI was also significantly higher among children who did not receive juice $(38.6 \%)$; tinned, powdered or fresh milk (38.1\%); other liquids (37.7\%); eggs $(39.4 \%)$; meat (beef, pork, lamb, chicken, etc) (38.2\%); pumpkin, carrots, squash (yellow or orange inside) (36.9\%); mangoes, papayas, other vitamin A fruits $(36.9 \%)$;

Table 1: Background characteristics of children

\begin{tabular}{|c|c|}
\hline Variables & Frequencies (\%) \\
\hline \multicolumn{2}{|c|}{ Children age (months) } \\
\hline $6-11$ & $844(36 \%)$ \\
\hline $12-17$ & $791(33.75 \%)$ \\
\hline $18-23$ & $709(30.25 \%)$ \\
\hline \multicolumn{2}{|l|}{ Sex of child } \\
\hline Male & $1185(50.55) \%$ \\
\hline Female & $1159(49.45 \%)$ \\
\hline \multicolumn{2}{|c|}{ Mother's educational status } \\
\hline No education & $376(16.04 \%)$ \\
\hline Primary & $695(26.65 \%)$ \\
\hline Secondary & $1081(46.12 \%)$ \\
\hline Higher & $192(8.19 \%)$ \\
\hline \multicolumn{2}{|c|}{ Father's educational status } \\
\hline No education & $601(25.64 \%)$ \\
\hline Primary & $692(29.52 \%)$ \\
\hline Secondary & $727(31.02 \%)$ \\
\hline Higher & $324(13.82 \%)$ \\
\hline \multicolumn{2}{|c|}{ Socio-economic status } \\
\hline Poorest & $494(21.07 \%)$ \\
\hline Poorer & $451(19.24 \%)$ \\
\hline Middle & $446(19.03 \%)$ \\
\hline Richer & $484(20.65 \%)$ \\
\hline Richest & $469(20.01 \%)$ \\
\hline \multicolumn{2}{|l|}{ Place of residence } \\
\hline Urban & $720(30.72 \%)$ \\
\hline Rural & $1624(69.28 \%)$ \\
\hline Total & 2344 \\
\hline
\end{tabular}

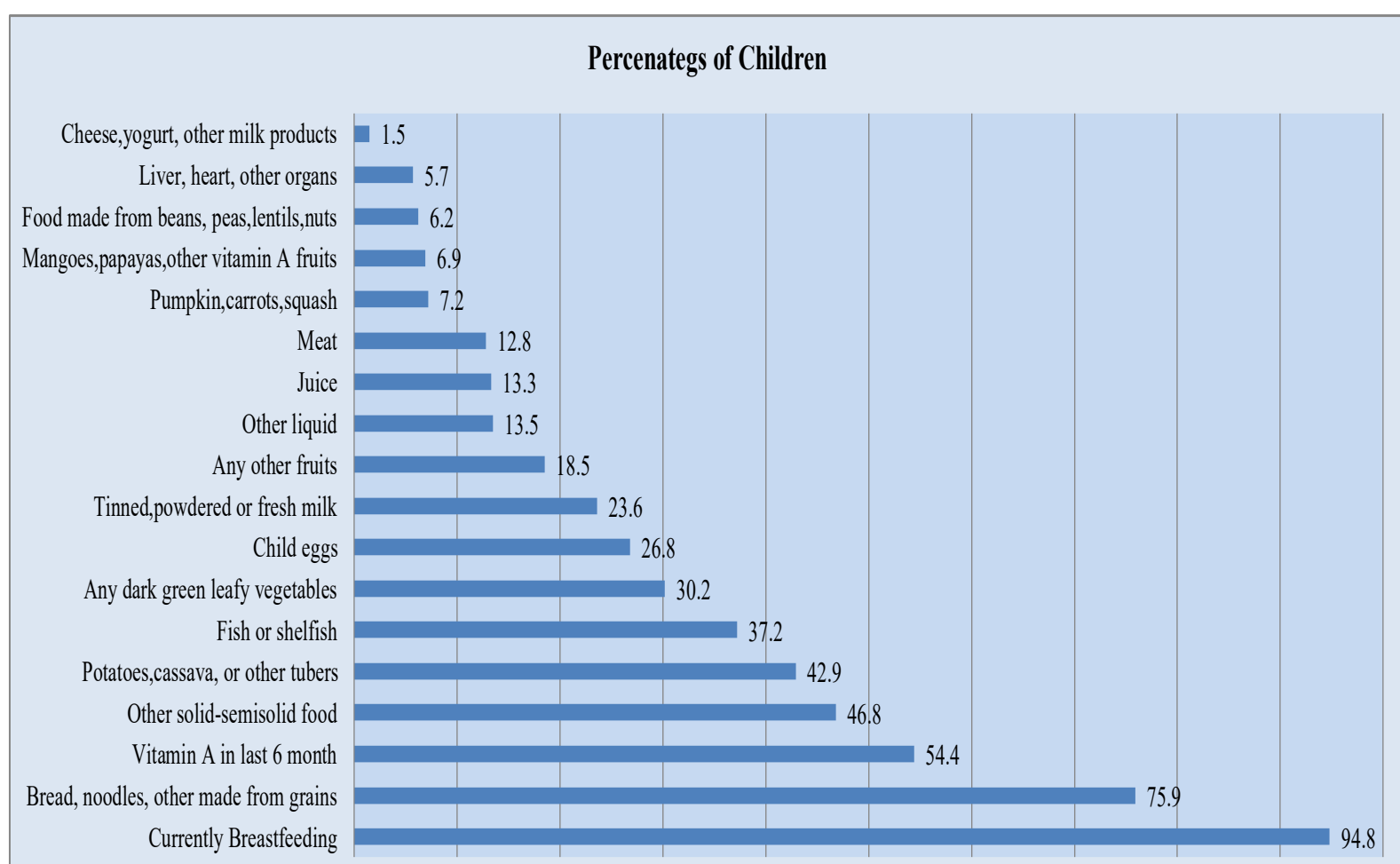

Figure 1: Percentage of children receiving nutritional items chidlren 
Chowdhury et al. a Household food insecurity and nutritional practice of children

Table 2: Prevalence of HHFI in terms of individual, household and community levels factors

\begin{tabular}{|c|c|c|c|}
\hline \multirow{2}{*}{ Variables } & \multicolumn{3}{|c|}{ Food insecurity } \\
\hline & Subject & Prevalence (95\% CI) & P values \\
\hline \multicolumn{4}{|c|}{ Children age (months) } \\
\hline $6-11$ & 310 & $39.0(35.0-43.1)$ & 0.094 \\
\hline $12-17$ & 251 & $33.1(29.3-37.2)$ & \\
\hline $18-23$ & 254 & $36.7(32.4-41.1)$ & \\
\hline \multicolumn{4}{|l|}{ Sex of child } \\
\hline Male & 397 & $35.1(32.0-38.4)$ & 0.271 \\
\hline Female & 418 & $37.5(34.0-41.1)$ & \\
\hline \multicolumn{4}{|c|}{ Mother's educational status } \\
\hline No education & 220 & $58.5(52.1-64.7)$ & $<0.001$ \\
\hline Primary & 308 & $45.0(40.3-49.8)$ & \\
\hline Secondary & 269 & $26.5(23.4-29.8)$ & \\
\hline Higher & 18 & $9.6(5.7-15.7)$ & \\
\hline \multicolumn{4}{|c|}{ Father's educational status } \\
\hline No education & 314 & $52.7(47.9-57.5)$ & $<0.001$ \\
\hline Primary & 293 & $42.9(38.7-47.2)$ & \\
\hline Secondary & 176 & $25.9(22.1-30.0)$ & \\
\hline Higher & 32 & $10.3(6.9-15.1)$ & \\
\hline \multicolumn{4}{|c|}{ Socio-economic status } \\
\hline Poorest & 308 & $63.0(58.2-67.7)$ & $<0.001$ \\
\hline Poorer & 222 & $49.2(43.7-54.8)$ & \\
\hline Middle & 140 & $32.9(27.9-38.4)$ & \\
\hline Richer & 106 & $19.8(16.0-24.3)$ & \\
\hline Richest & 39 & $9.3(6.5-13.2)$ & \\
\hline \multicolumn{4}{|l|}{ Place of residence } \\
\hline Urban & 187 & $24.7(20.1-30.0)$ & $<0.001$ \\
\hline Rural & 628 & $39.6(36.5-42.8)$ & \\
\hline Total & 815 & $36.3(33.6-39.0)$ & \\
\hline
\end{tabular}

Note: Values in parenthesis indicate Confidence Interval (CI)

liver, heart, other organs $(36.8 \%)$ and fish or shellfish $(38.1 \%)$. In contrast, HHFI found significantly more prevalent among breastfed children $(37.0 \%)$.

Association between HHFI and covariates (outcomes based on binary logistic regression analysis)

Significant variables in bivariate analysis were considered for binary logistic regression analysis (Table 4). As indicated in Table 4, children of illiterate mothers (adjusted OR: 2.20, 95\% CI: 1.17-4.10) and/or fathers (adjusted OR: $2.27,95 \%$ CI: 1.41-3.66) were more at risk of experiencing HHFI. Socio-economically poor children (adjusted OR: 11.35, 95\% CI: 7.20-17.91) were more vulnerable to HHFI. A lower chance of being HHFI was observed among rural children (adjusted OR: 0.72, 95\% CI: 0.57-0.93).

According to crude model (Table 5), children who were not given juice (crude OR: 2.46, 95\% CI: 1.79-3.37); tinned, powdered or fresh milk (crude OR: 1.28, 95\% CI: 1.03-1.60); other liquid (crude OR: $1.37,95 \%$ CI: $1.02-$ 1.76); eggs (crude OR: 1.45, 95\% CI: 1.17-1.80) and meat (beef, pork, lamb, chicken, etc) (crude OR: 1.55, 95\% CI: 1.14-2.11) had more chance to experience HHFI. In adjusted model, children who did not receive juice (adjusted OR: 1.54, 95\% CI: 1.09-2.16) were more likely to experience HHFI.

\section{Discussion}

In this study, we considered 18 nutritional indicators which were strongly recommended for the children 6-23 months of age. ${ }^{21}$ We observed that most of the nutritional items were poorly received by the children. Studies previously conducted in Bangladesh found similar results. ${ }^{22}$ Similar findings have also been noted in most South Asian countries, such as, India, Pakistan, Sri Lanka and Nepal. ${ }^{23-26}$ Global foods prices have increased by more than $10 \%$ along with social, political and environmental vulnerabilities adversely affecting food and nutrition security throughout South Asian regions. ${ }^{27}$ In this study, approximately $36.3 \%$ children age 6-23 months were estimated to be food insecure. The prevalence of under-five year old children HHFI was also significantly higher in some developing countries, such as, Brazil (51.7\%), Ghana (69.9\%), Ethiopia $(66.4 \%), \underset{160}{\text { Vietnam }}(40.3 \%)$ and Nepal $(69.0 \%))^{6,16,18,28}$

Our study showed that food insecurity was more prevalent among the children of illiterate parents, socio-economically poor families and rural dwelling. The findings were consistent with a study in Nepal that suggested that parent's educational status and socio-economic status were significantly associated with HHFI. ${ }^{18}$ Similar results have been observed in Organization for Economic Co-operation and Development (OECD) countries, such as, The Unites States of America; households with illiterate mothers are vulnerable to food insecurity ${ }^{29}$. Illiterate mothers with poor socioeconomic status reflect inadequate CFP. ${ }^{30}$ Some literature suggests that, a large proportion of children from socio-economically poor households, who are living beyond the poverty line, are food insecure. $^{31-33}$

In this study, a significantly higher proportion of children were found to be food insecure, as they did 
Chowdhury et al. a Household food insecurity and nutritional practice of children

Table 3: Prevalence of HHFI based on nutritional practice of children

\begin{tabular}{|c|c|c|c|}
\hline \multirow{2}{*}{ Indicators } & \multicolumn{3}{|c|}{ Food insecurity } \\
\hline & Subject & Prevalence $(95 \%$ CI) & P values \\
\hline \multicolumn{4}{|l|}{ Juice } \\
\hline Given & 54 & $20.4(15.3-26.7)$ & $<0.001$ \\
\hline Not given & 761 & $38.6(35.8-41.5)$ & \\
\hline \multicolumn{4}{|c|}{ Tinned, powdered or fresh milk } \\
\hline Given & 161 & $30.8(26.3-35.8)$ & 0.007 \\
\hline Not given & 654 & $38.1(35.2-41.1)$ & \\
\hline \multicolumn{4}{|l|}{ Other liquid } \\
\hline Given & 82 & $26.9(21.3-33.4)$ & 0.002 \\
\hline Not given & 733 & $37.7(34.9-40.6)$ & \\
\hline \multicolumn{4}{|c|}{ Bread, noodles, other made from grains } \\
\hline Given & 644 & $38.1(35.2-41.1)$ & 0.005 \\
\hline Not given & 171 & $30.8(26.4-35.6)$ & \\
\hline \multicolumn{4}{|c|}{ Potatoes, cassava, or other tubers } \\
\hline Given & 361 & $36.6(32.8-40.6)$ & 0.822 \\
\hline Not given & 454 & $36.1(32.8-39.5)$ & \\
\hline \multicolumn{4}{|l|}{ Eggs } \\
\hline Given & 172 & $27.1(23.1-31.5)$ & $<0.001$ \\
\hline Not given & 643 & $39.4(36.3-42.6)$ & \\
\hline \multicolumn{4}{|c|}{ Meat (beef, pork, lamb, chicken, etc) } \\
\hline Given & 72 & $23.3(18.2-29.3)$ & $<0.001$ \\
\hline Not given & 743 & $38.2(35.4-41.1)$ & \\
\hline \multicolumn{4}{|c|}{ Pumpkin, carrots, squash (yellow or orange inside) } \\
\hline Given & 49 & $28.1(20.9-36.6)$ & 0.050 \\
\hline Not given & 766 & $36.9(34.1-39.7)$ & \\
\hline \multicolumn{4}{|c|}{ Any dark green leafy vegetables } \\
\hline Given & 247 & $38.0(33.8-42.5)$ & 0.319 \\
\hline Not given & 568 & $35.5(32.5-38.7)$ & \\
\hline \multicolumn{4}{|c|}{ Mangoes, papayas, other vitamin A fruits } \\
\hline Given & 42 & $27.5(20.7-35.5)$ & 0.027 \\
\hline Not given & 773 & $36.9(34.1-39.8)$ & \\
\hline \multicolumn{4}{|c|}{ Any other fruits } \\
\hline Given & 136 & $33.4(27.7-39.5)$ & 0.287 \\
\hline Not given & 679 & $36.9(34.0-39.9)$ & \\
\hline \multicolumn{4}{|c|}{ Liver, heart, other organs } \\
\hline Given & 31 & $26.9(18.8-36.9)$ & 0.049 \\
\hline Not given & 784 & $36.8(34.1-39.6)$ & \\
\hline \multicolumn{4}{|c|}{ Fish or shellfish } \\
\hline Given & 282 & $33.1(29.1-37.4)$ & 0.048 \\
\hline Not given & 533 & $38.1(35.0-41.4)$ & \\
\hline \multicolumn{4}{|c|}{ Food made from beans, peas, lentils, nuts } \\
\hline Given & 47 & $31.2(22.8-41.0)$ & 0.266 \\
\hline Not given & 768 & $36.6(33.9-39.4)$ & \\
\hline \multicolumn{4}{|c|}{ Cheese, yogurt, other milk products } \\
\hline Given & 9 & $27.1(13.1-47.7)$ & 0.348 \\
\hline Not given & 806 & $36.4(33.7-39.1)$ & \\
\hline \multicolumn{4}{|c|}{ Other solid-semisolid food } \\
\hline Given & 377 & $36.2(32.7-39.9)$ & 0.949 \\
\hline Not given & 438 & $36.3(33.0-39.8)$ & \\
\hline \multicolumn{4}{|c|}{ Currently breastfeeding } \\
\hline Yes & 779 & $37.0(34.2-39.8)$ & 0.007 \\
\hline No & 36 & $23.9(16.8-32.9)$ & \\
\hline
\end{tabular}

Note: Values in parenthesis indicate Confidence Interval (CI)

not receive most of the nutritional items. Despite impressive progress in agriculture since independence in 1971, food prices have rapidly increased in the last decade which has resulted in poverty and hunger in Bangladesh. $^{28}$ In addition, natural hazards, such as, environmental pollution, floods, global worming etc, sometimes hamper agricultural production which may cause HHFI. ${ }^{34}$ Bivariate analysis also showed the significant relationship between HHFI and breastfeeding status. A higher prevalence of breastfed children was South East Asia Journal of Public Health 2016;6(2):53-60 found to be food insecure. The immunological and nutritional characteristics of breastfeeding can protect children from continued nutritional hardship. However, continued breastfeeding due to a lack of food availability sometimes causes health hazards to children. ${ }^{35}$

In India, education has a significant impact on HHFI which is consistent with our study. ${ }^{36}$ The adjusted logistic model also showed that children of 
Chowdhury et al. * Household food insecurity and nutritional practice of children

Table 4: Association between HHFI and multilevel factors

\begin{tabular}{|c|c|c|c|c|}
\hline Variables & $\begin{array}{c}\text { Unadjusted ORs } \\
(95 \% \mathrm{CI})\end{array}$ & $P$ values & $\begin{array}{c}\text { Adjusted ORs } \\
(95 \% \mathrm{CI})\end{array}$ & P values \\
\hline \multicolumn{5}{|c|}{ Mother's educational status } \\
\hline No education & $4.60(2.52-8.40)$ & $<0.001$ & $2.20(1.17-4.10)$ & 0.013 \\
\hline Primary & $2.93(1.66-5.18)$ & $<0.001$ & $1.59(0.88-2.86)$ & 0.121 \\
\hline Secondary & $1.66(0.96-2.87)$ & 0.071 & $1.19(0.68-2.10)$ & 0.543 \\
\hline Higher & 1.00 & & 1.00 & \\
\hline \multicolumn{5}{|c|}{ Father's educational status } \\
\hline No education & $4.57(2.89-7.22)$ & $<0.001$ & $2.27(1.41-3.66)$ & 0.001 \\
\hline Primary & $4.12(2.66-6.39)$ & $<0.001$ & $2.36(1.50-2.56)$ & $<0.001$ \\
\hline Secondary & $2.18(1.42-3.36)$ & $<0.001$ & $1.64(1.05-2.56)$ & 0.028 \\
\hline Higher & 1.00 & & 1.00 & \\
\hline \multicolumn{5}{|c|}{ Socio-economic status } \\
\hline Poorest & $18.26(12.55-26.56)$ & $<0.001$ & $11.35(7.20-17.91)$ & $<0.001$ \\
\hline Poorer & $10.69(7.34-15.57)$ & $<0.001$ & $8.05(5.20-12.49)$ & $<0.001$ \\
\hline Middle & $5.04(3.44-7.41)$ & $<0.001$ & $4.24(2.75-6.55)$ & $<0.001$ \\
\hline Richer & $3.10(2.10-4.58)$ & $<0.001$ & $2.69(1.77-4.10)$ & $<0.001$ \\
\hline Richest & 1.00 & & 1.00 & \\
\hline \multicolumn{5}{|l|}{ Place of residence } \\
\hline Urban & 1.00 & & 1.00 & \\
\hline Rural & $1.79(1.47-2.18)$ & $<0.001$ & $0.72(0.57-0.93)$ & 0.01 \\
\hline
\end{tabular}

Note: $\dagger$ Adjusted for all the other variables shown in the table

Table 5: Association between HHFI and nutritional behavior of children

\begin{tabular}{|c|c|c|c|c|}
\hline Indicators & $\begin{array}{c}\text { Crude OR (95\% } \\
\text { CI) }\end{array}$ & P values & $\begin{array}{l}\text { Adjusted OR } \dagger \\
(95 \% \mathrm{CI})\end{array}$ & P values \\
\hline \multicolumn{5}{|l|}{ Juice } \\
\hline Given & 1.00 & & 1.00 & \\
\hline Not given & $2.46(1.79-3.37)$ & 0.000 & $1.54(1.09-2.16)$ & 0.014 \\
\hline \multicolumn{5}{|c|}{ Tinned, powdered or fresh milk } \\
\hline Given & 1.00 & & 1.00 & \\
\hline Not given & $1.28(1.03-1.60)$ & 0.024 & $0.92(0.72-1.16)$ & 0.474 \\
\hline \multicolumn{5}{|l|}{ Other liquid } \\
\hline Given & 1.00 & & 1.00 & \\
\hline Not given & $1.37(1.02-1.76)$ & 0.037 & $0.96(0.71-1.31)$ & 0.796 \\
\hline \multicolumn{5}{|c|}{ Bread, noodles, other made from grains } \\
\hline Given & 1.00 & & 1.00 & \\
\hline Not given & $0.59(0.47-0.75)$ & $<0.001$ & $0.64(0.49-0.82)$ & $<0.001$ \\
\hline \multicolumn{5}{|l|}{ Eggs } \\
\hline Given & 1.00 & & 1.00 & \\
\hline Not given & $1.45(1.17-1.80)^{*}$ & 0.001 & $0.99(0.78-1.27)$ & 0.981 \\
\hline \multicolumn{5}{|l|}{ Meat } \\
\hline Given & 1.00 & & 1.00 & \\
\hline Not given & $1.55(1.14-2.11)$ & 0.005 & $1.38(0.97-1.96)$ & 0.074 \\
\hline \multicolumn{5}{|c|}{ Pumpkin, carrots, squash } \\
\hline Given & 1.00 & & 1.00 & \\
\hline Not given & $1.02(0.71-1.46)$ & 0.933 & $0.74(0.49-1.11)$ & 0.149 \\
\hline \multicolumn{5}{|c|}{ Mangoes, papayas, other vitamin A fruits } \\
\hline Given & 1.00 & & 1.00 & \\
\hline Not given & $1.20(0.82-1.76)$ & 0.342 & $1.09(0.73-1.66)$ & 0.655 \\
\hline \multicolumn{5}{|c|}{ Liver, heart, other organs } \\
\hline Given & 1.00 & & 1.00 & \\
\hline Not given & $1.23(0.78-1.94)$ & 0.366 & $0.91(0.52-1.57)$ & 0.728 \\
\hline \multicolumn{5}{|c|}{ Fish or shellfish } \\
\hline Given & 1.00 & & 1.00 & \\
\hline Not given & $1.17(0.96-1.43)$ & 0.099 & $1.17(0.94-1.45)$ & 0.150 \\
\hline \multicolumn{5}{|c|}{ Currently breastfeeding } \\
\hline Yes & 1.00 & & 1.00 & \\
\hline No & $0.81(0.54-1.21)$ & 0.296 & $1.02(0.66-1.55)$ & 0.939 \\
\hline
\end{tabular}

$\uparrow$ Adjusted with multilevel factors, such as, mother's educational status, father's educational status, socio-economic status and place of residence

rural settlements were at a reduced risk of experiencing HHFI. However, in unadjusted model, urban children were least risk. Nowadays, women in rural South East Asia Journal of Public Health 2016;6(2):53-60 environments are expected to undertake multiple tasks, such as, food production, handicraft and these all contribute to domestic economy. More than half of 
Bangladeshi women living in rural areas are housewives are responsible to ensure the food requirements of their dependents in situations of economic deterioration. ${ }^{37}$ According to crude regression model, children who did not receive most of the nutritional items had more chance to experience HHFI and in adjusted model, juice was not received by the food insecure children. Nevertheless, in The United States of America, the introduction of juice and HHFS did not show any significant association. ${ }^{29}$

Insufficient domestic production of non-cereal foods (for example, pulses, fruits, meat, milk, eggs etc.), lower socio-economic status, and lack of nutritional knowledge reflect HHFI. ${ }^{38}$ This study suggests that nutrition surveillance needs to be strengthened under government structures to allow early detection of changes in nutrition, health, and food security status. ${ }^{39}$ The existing food safety net program has to be extended in targeted areas where child malnutrition and HHFI are most prevalent. $^{45}$ Gardening through women participation needs to spread in rural, urban and suburban areas to improve nutritional security. ${ }^{40}$

This study has several strengths. The main strength of the study was to investigate the pervasive relationship between nutritional factors and HHFI in Bangladesh using a large national representative data. Several limitations of the study are worth mentioning. These include the cross-sectional nature of the data. Most of the nutritional items were given to the children in the 24 -hours preceding the survey; however, the children could occasionally receive some other foods but simply did not the previous day. Another limitation involves information bias, which may result from self-reporting age, education, household assets, nutritional indicators etc. Despite these limitations, our study has been able to draw a detailed picture of the association between HHFI and the nutritional behavior of children 6-23 months of age in Bangladesh.

\section{Conclusion}

A large number of children in Bangladesh experience HHFI and this condition hampers proper nutritional practice among children in households. HHFI is found to be strongly associated with several individual, household and community factors, such as, parental education, socio-economic status and place of residence. These factors should be considered while developing strategies/interventions to address the issue of a child's HHFI status. Collaborations among various stakeholders (e.g. public and private level organizations) and strengthening of existing programs are also extremely important and necessary. Moreover, longitudinal studies are recommended to assess the cause-effect relationship between plausible factors and HHFI in Bangladesh. Finally, in Bangladesh, further investigations on HHFI are needed. Such research will inspire ingenuity in developing effective strategies to improve the HHFS status of children.

\section{Competing interest}

The authors declared they have no conflict of interest.

\section{References}

1. Saaka M, Osman SM. Does household food insecurity affect the nutritional status of preschool children aged 6-36 months? Int J Pop Res. 2013; Article ID 304169.12.

2. Levinson FJ, Hussain D. Protecting and Promoting Food Security and Nutrition among Families and Children in Bangladesh. Final Evaluation. Thematic Window: Children, Food Security and Nutrition. New York: MDGSecretariat, 2013.

3. Islam MM, Alam M, Tariquzaman M, Kabir MA, Pervin R, Begum M, et al. Predictors of the number of under-five malnourished children in Bangladesh: application of the generalized Poisson regression model. BMC Public Health 2013;13:11.

4. Mancharia CW, Kog-Makau W, Murok NM. Dietary intake, feeding and care practices at children in Kathonzweni, Division, Makuenl, district, Kenya. East Africa Med J 2004; 81:5-6.

5. Khan MMH. Urban health in megacities of developing countries. Public Health Forum 2012; 20: 29.

6. World Food Programme. Food Security at a Glance. Bangladesh Poverty Map 2005 (percent below the lower poverty line). Dhaka: WFP, 2005.

7. World Health Organization. Indicators for Assessing Infant and Young Child Feeding Practices: Conclusions of a Consensus Meeting Held 6-8 November 2007 in Washington D.C., USA. Geneva: WHO, 2008.

8. Saha KK, Frongillo EA, Alam DS, Arifeen SE, Persson LA, Rasmussen KM. Appropriate infant feeding practices result in better growth of infants and young children in rural Bangladesh. Am J Clin Nutr 2008; 87:1852-9.

9. Srivastava N, Sandhu A. Index for Measuring Child Feeding Practices. Indian J Pediatr 2007; 74 (4):363-8.

10. Belachew $\mathrm{T}$, Lindstrom D, Hadley C, Gebremariam A, Kasahun W, Kolsteren P. Food insecurity and linear growth of adolescents in Jimma Zone, Southwest Ethiopia. Nutr J 2013;12:55.

11. Hannum EC, Liu J, Frongillo E. Poverty, Food insecurity and nutritional deprivation in rural China: Implications for children's literacy achievement. Int J Educ Dev 2014;34:90-7.

12. Schneider K, Roy PK, Hasan D. Food insecurity and child malnutrition in North Bangladesh. http://www.ennonline.net/fex/36/food (accessed Dec 2016)

13. Ilaboya IR, Atikpo E, Omofuma FE, Asekhame FF, Umukoro L. Causes, effects and way forward to food insecurity. IJEE 2012; 3(2):180-188.

14. Melchior M, Chastang JF, Falissard B, Galera C, Tremblay RE, Cote SM, et al. Food insecurity and children's mental health: A prospective birth cohort study. PLOS ONE. 2012; 7(12).

15. Food Security in Developing Countries. Parliamentary Office of Science and technology. http://www.parliament.uk (accessed Dec 2016)

South East Asia Journal of Public Health 2016;6(2):53-60 
16. dos Santos LP, Gigante DP. Relationship between food insecurity and nutritional status of Brazilian children under the age of five. Rev Bras Epidemiol 2013; 16(4):984-94.

17. Lindsay AC, Ferarro M, Franchello A, Barrera RL, Machado MMT, Pfeiffer ME, et al. Child feeding practices and household food insecurity among low-income mothers in Buenos Aires, Argentina. Cien Saude Colet 2012;17(3): 661-9.

18. Osei A, Pandey P, Spiro D, Nielson J, Shrestha R, Talukder Z, et al. Household food insecurity and nutritional status of children aged 6 to 23 months in Kailali District of Nepal. Food Nutr Bull 2010:31(4):483-93.

19. Saha KK, Frongillo EA, Alam DS, Arifeen SE, Persson LÅ, Rasmussen KM. Household food security is associated with infant feeding practices in rural Bangladesh. J Nutr 2008; 138 (7):1383-90.

20. National Institute of Population Research and Training (NIPORT), Mitra and Associates, and ICF International. Bangladesh Demographic and Health Survey 2011. Dhaka, Bangladesh and Calverton, Maryland, USA: NIPORT, Mitra and Associates, and ICF International, 2013.

21. Boyle M, Celano G, Cooper E, Phillips KD, Trotter M, Stan SV. Best Practices for Healthy Eating. Nemours-A Children's Health System. http://www.delaware211.org (accessed Dec 2016)

22. Kabir I, Khanam M, Agho KE, Mihrshahi S, Dibley MJ, Roy SK. Determinants of inappropriate complementary feeding practices in infant and young children in Bangladesh: secondary data analysis of Demographic Health Survey 2007. Matern Child Nutr 2012; 8 (Suppl. 1):11-27.

23. Patel A, Pusdekar Y, Badhoniya N, Borkar J, Agho KE, Dibley MJ. Determinants of inappropriate complementary feeding practices in young children in India: secondary analysis of National Family Health Survey 2005-2006. Matern Child Nutr 2012; 8(1):28-44.

24. Joshi N, Agho KE, Dibley MJ, Senarath U, Tiwari K. Determinants of inappropriate complementary feeding practices in young children in Nepal: secondary data analysis of Demographic and Health Survey 2006. Matern Child Nutr 2012; 8 (1):45-59.

25. Senarath U, Godakandage SSP, Jayawickrama H, Siriwardena I, Dibley MJ. Determinants of inappropriate complementary feeding practices in young children in Sri Lanka: secondary data analysis of Demographic and Health Survey 2006-2007. Matern Child Nutr 2012; 8(1):60-77.

26. Hazir T, Senarath U, Agho K, Akram DS, Kazmi $\mathrm{N}$, Abbasi S, et al. Determinants of inappropriate timing of introducing solid, semi-solid or soft food to infants in Pakistan: Secondary data analysis of Demographic and Health Survey 2006-2007. Matern Child Nutr 2012; 8(1):78-88.

27. World Bank. Food Security in South Asia. http:// www.worldbank.org/en/news/ feature/2012/10/22/food-security-south-asia (accessed Dec 2016)

28. Ali D, Saha KK, Nguyen PH, Diressie MT, Ruel MT, Menon P, et al. Household food insecurity is associated with higher child undernutrition in Bangladesh, Ethiopia, and Vietnam, but the effect is not mediated by child dietary diversity. $J$ Nutr 2013;143:1-7.

29. Gross RS, Mendelsohn AL, Fierman AH, Racine $\mathrm{AD}$, Messito MJ. Food insecurity and obesogenic maternal infant feeding styles and practices in low-income families. Pediatrics 2012;130(2):554 -61 .

30. Ng CS, Dibley MJ, Agho KE. Complementary feeding indicators and determinants of poor feeding practices in Indonesia: a secondary analysis of 2007 Demographic and Health Survey data. Public Health Nutr 2011; 15(5):827 -39 .

31. Slack KS, Yoo J. Food hardships and child behavior problems among low-income children. Inst Res Poverty 2004;4:1290.

32. Matheson DM, Varady J, Varady A, Killen JD. Household food security and nutritional status of Hispanic children in the fifth grade. Am J Clin Nutr 2002; 76:210-7.

33. Rose D. Economic determinants and dietary consequences of food insecurity in the United States. JNutr 1999; 129:517-20.

34. CGIRA. Climate change, agriculture and food security. https://ccafs.cgiar.org (accessed Dec 2016)

35. Hong R, Banta JE, Betancourt JA. Relationship between household wealth inequality and chronic childhood under-nutrition in Bangladesh. Int $J$ Equity Health 2006; 5:15.

36. Chinnakali P, Upadhyay RP, Shokeen D, Singh K, Kaur M, Singh AK, et al. Prevalence of household-level food insecurity and its determinants in an urban resettlement colony in North India. J Health Popul Nutr 2014;32(2):227 -36 .

37. Alam ATMA. Women's agency and household food security in changing rural Bangladesh. https://www.linkedin.com/ pulse/20141009115301-30938971-women-sagency-and-household-food-security-in-changing -rural-bangladesh (accessed Dec 2016)

38. Begum MEA, Hossain MI, Haese LD. Food security in Bangladesh: Present status and trend. Progress Agric 2013; 24(1 \& 2): 263-71.

39. UNICEF: Child malnutrition and household food insecurity remain major concerns for Bangladesh. http://www.unicef.org/media/ media 48981.html (accessed Dec 2016)

40. Talukder A, de Pee S, Taher A, Hall A, Moench-Pfanner R, Bloem MW. Improving food and nutrition security through homestead gardening in rural, urban and peri-urban areas in Bangladesh. New York: Helen Keller International, 1999. 